Francisco Javier Sánchez Martín

Universidad de Murcia

\title{
Las divisiones menores del tiempo: aspectos terminológicos y lexicográficos ${ }^{*}$
}

Palabras clave: terminología, lexicología, lexicografía

\section{Introducción}

Al igual que los problemas de medición y construcción llevaron a las primeras consideraciones instrumentales de la ciencia geométrica -recuérdese el significado etimológico del término geometría 'medida de la tierra'-, la naturaleza del tiempo y los procedimientos para su medida han intrigado al hombre en todas las épocas históricas (Muñoz Box, 2002). Las matemáticas nacen por la necesidad de contar, medir y comparar, por eso Pedro de Medina nos recuerda en su Arte de navegar que «escripto está en el Libro de la Sabiduría que Dios hizo todas las cosas en número, peso y medida. Por tanto, sin saber los números no podemos saber nada del tiempo, de las horas, ni de los movimientos y otras cosas, de lo qual paresce que, sin sciencia de contar, no podemos algo saber» (Medina, 1545:34v).

Por tanto, si la necesidad de reponer los lindes de los campos tras las inundaciones del Nilo lleva a los egipcios a las elaboraciones geométricas ${ }^{1}$, el desarrollo de otros aspectos apremiantes para el hombre va irremediablemente

* Este trabajo es posible merced a los proyectos de investigación 11845/PHCS/o9, financiado por la Fundación Séneca, y FFI2010-16324/FILO (Dirección General de Investigación, Ministerio de Ciencia e Innovación).

1 «Los primeros inventores de esta sciencia del agrimensura son los egipcios, los quales, por causa de las grandes crescidas de el río Nilo con que se gastavan qualesquiera límites y términos de aquellos fertilíssimos campos qu'en su ribera hay, eran forçados cada día de tornar de nuevo a medir la tierra y distribuyr rectamente a cada uno la porción que le tocava, de donde tomó su ethimología la tan celebrada arte de la geometría» (Collado, 1592: 68r). 
unido a la medida del tiempo. Por ejemplo, las tareas agrícolas, con los tiempos idóneos para las labores de siembra y cosecha, o las ganaderas, además de otras previsiones climatológicas, estaban -y aun siguen- sujetas al calendario, a la vez que con éste se regulaba también el cobro de los tributos ${ }^{2}$.

Por otro lado, es primitiva la asociación establecida entre las nociones de tiempo y duración, que es un concepto más concreto, más primitivo que el de tiempo, nacido de abstracciones de las duraciones. De hecho, las primeras medidas relacionadas con el trabajo agrícola están vinculadas a esta conceptualización de duración, constatable en los términos metrológicos mansio o jornada, yuguero (o yugada) y buebra, si nos atenemos a las definiciones proporcionadas por Nebrija. Por lo que respecta a las primeras, del sentido 'camino de un día' se pasa al de 'tiempo de duración del trabajo diario'. Con respecto a las segundas, de denotar 'tierra que un día podía labrar una yunta de bueyes' a expresar la medida superficial, equivalente a «doscientos cuarenta pies de longitud y cientoveinte de anchura, esto es, dos «actus» cuadrados» (Nebrija, 1510: s. v. iugerum).

\begin{tabular}{|l|l|}
\hline Nebrija (1492) & Nebrija (1495) \\
\hline \multirow{2}{*}{ mansio. por la jornada } & jornada. camino de un día.dieta. mansio \\
\cline { 2 - 2 } & dieta jornada.iter unius diei \\
\hline \multirow{3}{*}{ iugerum.i. por una obrada de tierra } & obra el trabajo que allí se pone.opera.e \\
\cline { 2 - 2 } & obrada cosa por uebras.operosus.a.um \\
\cline { 2 - 2 } & obrada de tierra.iugerum.i \\
\hline
\end{tabular}

Las conexiones entre distancia (espacio) y tiempo son estrechas, de hecho ambas magnitudes cuantificables eran empleadas en la antigua Grecia como medida del movimiento (Lindberg, 2002: 371). Por abstracto que resulte el tiempo, este concepto necesita de una representación material para lo cual ya Aristóteles se servía de líneas, al igual que Euclides las empleaba para figurar las magnitudes numéricas (Lindberg, 2002: 375).

En definitiva el hombre precisa echar mano de unas medidas exactas por medio de las cuales contar el tiempo, esto es, para organizar desde los aspectos más cotidianos a las más diversas necesidades sociales:

Por causa que las cosas necessarias a la vida del hombre fuessen distinguidas por alguna cuenta y medida, dividieron los

2 Las premáticas regulan el pago del diezmo: «Que sobre el pagarse los diezmos y el tiempo que se han de pagar se guarden las leyes d'estos reynos. Ley II, título III, libro I» (Martínez de Burgos, 1551: XLVIIIv). 
antiguos el tiempo en ciertas partes, como más les plugo. Assí como en edades, siglos, eras, indictiones, lustros o olimpias, años, meses, semanas, días, quadrantes, horas, puntos, momentos, uncias, áthomos. (Pérez de Moya, 1573: 720)

En este trabajo, para el análisis terminológico de las unidades con que se dividían las horas del día (átomo, cuadrante, momento, punto y uncia) partimos de las principales fuentes de estudio medievales y renacentistas, lo que nos permitirá realizar una descripción de las mismas, así como estudiar sus relaciones y, por último, analizar la recepción de este vocabulario en los primeros diccionarios del español.

\section{Las fuentes de estudio medievales y renacentistas}

\subsection{El enciclopedismo medieval: San Isidoro y Bartolomé Ánglico}

Esta concepción del tiempo y su división, que sigue la estela de los clásicos, está presente en el movimiento intelectual de la Alta Edad Media representado por las figuras de San Isidoro y Bartolomé Ánglico, cuyas obras suelen incluirse dentro de la corriente del enciclopedismo medieval. En ambos casos se trata de

[...] recopilaciones que tratan de presentar de manera ordenada la totalidad de los saberes; con independencia de su extensión y de sus contenidos [...], son obras de compilación y vulgarización, cuya finalidad es poner al alcance del público culto de la época todo el saber, especialmente el científico. (Sánchez González, 2007: 10)

Una muestra de la transmisión cultural de este léxico es su recepción en la obra de Isidoro de Sevilla (c. 560-636), quien trabajó a partir de un conjunto de fuentes bastante heterogéneo para constituir sus Etimologías, a partir de la cual se origina una familia histórica de obras que repiten contenidos y fuentes, en gran medida porque estas primeras enciclopedias buscaban preservar y difundir la herencia grecolatina (Gutiérrez Rodilla, 2007: 43, 139; Sánchez González, 2007: 45-46).

Según vimos, el transcurso del tiempo tiene su transcedencia en el orden jurídico. Conocedor de estas implicaciones, Isidoro inserta en el libro V, dedicado al Derecho, los contenidos de la cronometría para lo que recopila los 
vocablos más usuales de este campo relativos a momentos, horas, días, meses, años, lustros, siglos y edades. Las unidades menores aparecen explicadas seguiendo el procedimento etimológico habitual: momento 'movimiento' [momentum (<moveo + mentum) es contracción de movimentum (Ernout-Meillet,

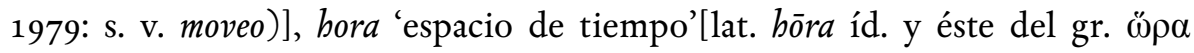
'espacio de tiempo' (Corominas y Pascual, 1980-1991: s. v.)] y día 'espacio de tiempo equivalente a veinticuatro horas' [(lat. vg. dīa, lat. dièes, relacionado con diu 'largo tiempo'(Corominas y Pascual, 1980-1991: s. v.)]3.

Momento es el tiempo más pequeño y reducido, y recibe su nombre del «movimiento» de los astros. Es la fracción más reducida de una hora dividida en sus intervalos más breves, cuando un instante ha terminado y da comienzo otro. El nombre de hora es griego, pero en latín suena igual. La «hora» es un límite de tiempo, del mismo modo que la «orilla» es un límite del mar, de los ríos o de los vestidos. (Oroz Reta y Marcos Casquero, 1982-1983: 527)4

Día es la presencia del sol, o el sol sobre la tierra, como la noche es el sol bajo la tierra. [...] El día tiene veinticuatro horas; y cada una de sus partes, doce. [...] Día deriva de los «dioses», cuyos nombres consagraron los romanos a algunos astros. (Oroz Reta y Marcos Casquero, 1982-1983: 527-529)

Será en el libro XIII, dedicado al mundo y sus partes, donde destina un capítulo específico a los cuerpos indivisibles denominados átomos, que «existen en los cuerpos, en el tiempo y en el número»; y explica:

En el tiempo, el átomo lo concebimos de la siguiente manera: el año lo divides en meses; los meses, en días; los días, en horas; todavía las horas admiten una división, hasta que llegas a un punto de tiempo y a un espacio temporal tan breve que no cabe la posibilidad de que se produzca una nueva medida, por muy pequeña que sea, porque ya no puede dividirse más. Este es el átomo del tiempo. (Oroz Reta y Marcos Casquero, 1982-1983: 127) quartus, dans le dérivé diurnus et peut-être dans Dius Fidius» (Ernout-Meillet, 1979: s. v. diēs).

4 Nótese la apreciación fonética de Isidoro, que observaremos en el pasaje dedicado a la definición de la bora en otros autores, por ejemplo, Pérez de Moya (1573: 721): «Hállase escripto acerca de los latinos sin aspiración, y entonces quiere dezir la costa de la mar o aquella parte que es término de alguna cosa». Este y otros son testimonios palpables de la transmisión posterior de estas fuentes. 
Hacia 1240 aparece el Libro de las propiedades de las cosas de Bartolomé Ánglico, enciclopedia que gozó de extraordinaria recepción en el occidente europeo hasta el siglo XVI incluido debido al didactismo, el orden lógico y su claridad

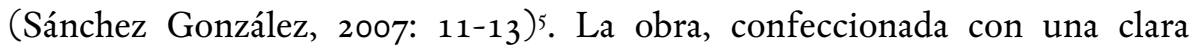
finalidad moral o religiosa, se estructura en diecinueve libros que ofrecen «un esquema que parte del origen, Dios, y va descenciendo al hombre y a la tierra, es decir de lo incorpóreo a lo corpóreo» (Sánchez González, 2007: 14). De todos ellos nos interesa destacar por su contenido el libro noveno, que está dedicado a la temática del tiempo y se estructura en capítulos que comprenden su concepción, descripción y división, así como las relaciones con otra magnitud física: «Del tiempo \& mouimiento».

El capítulo IX, «Del primero mes del ano \& de sus propiedades», comienza con la explicación del significado de mes de acuerdo con su etimología:

Mes es vn no $<\mathrm{m}>$ bre griego $\mathrm{q}<\mathrm{ue}>$ es tomado del no $<\mathrm{m}>$ bre de la luna / $\mathrm{q}<\mathrm{ue}>$ es llamada en griego mene. los yudios cue $<\mathrm{n}>\mathrm{ta}<\mathrm{n}>$ sus meses segund el curso del sol / mas ellos los no $<\mathrm{m}>$ bran segund el curso de la luna (Ánglico, c. 1240: 135v ${ }^{6}$

Antes de ofrecer la exposición exhaustiva de los nombres de cada mes, inserta la división de las unidades temporales menores:

El mes pues co $<\mathrm{n}>$ tiene iiij. semanas \& la semana $\mathrm{co}<\mathrm{n}>$ tiene .vij. dias. \& el dia contiene .iiij. quadra $<\mathrm{n}>$ tes. \& el quadra $<\mathrm{n}>$ te co $<\mathrm{n}>$ tiene.$v j$. oras. vna ora $\mathrm{co}<\mathrm{n}>$ tiene .iiij. puntos vn punto co $<$ n $>$ tiene.$x$. mome $<$ n $>$ tos vn mome $<$ n $>$ to co $<$ n $>$ tiene.$x i j$. vncias vna vncia $c 0<\mathrm{n}>$ tiene .xlvij. antonnes $\&$ el antonno es ta $<\mathrm{n}>$ pequeno $\mathrm{q}<\mathrm{ue}>$ no se puede mas diuidir. (Ánglico, $c$. 1240: $135 \mathrm{v}$ )

No obstante, Ánglico se había ocupado ya de la concepción del átomo como partícula física dentro del libro III, «Que trata del anima \& de sus propiedades», dedicado al hombre y en concreto en el capítulo IV «Que cosa es anima segund la opinion de los antiguos dotor[e]s»:

Ca cerca desta materia se leen diuersas sentencias \& quasi co $<\mathrm{n}>$ trarias de los antiguos philosofos [...] Eraclito fisico llama nuestra alma luz. o centella de essencia. mas Domocrito dixo que

5 Esta investigadora detalla las cifras de ediciones en latín y en las lenguas vernáculas, al tiempo que recalca que el siglo XIII supuso la época de mayor auge del género.

6 Las referencias siguen el texto preparado por Sánchez y Herrera (1999). 
era vn espirito compuesto $\mathrm{d}<\mathrm{e}>$ muy pequenas partes llamadas atomos como son aquellas pequenas partezillas que vemos mouer en el rayo solar \& dezia que por la facilidad de su mouimiento mouia el cuerpo a todo lugar. (Ánglico, c. 1240: 24v)

Las autoridades manejadas para tal cuestión son abundantes e ilustrativas de su bagaje: Platón, Zenón, Pitágoras, Heráclito, Demócrito, Perménides, etc.; sin embargo, la autoridad más citada es San Isidoro, como ha mostrado Sánchez González (2007).

\subsection{Los tratados renacentistas}

En el paso de la época medieval a la renacentista el impulso que cobra la actividad comercial en los centros urbanos acrecienta el interés por el aprendizaje del arte mercantil y las cuestiones metrológicas, lo que explica el auge de las aritméticas comerciales y, en consecuencia, la divulgación de los contenidos (Sánchez Martín, en prensa). Sin embargo, junto a estas obras aparecen otras, compuestas desde comienzos de siglo, cuyo interés radica en estudiar los cómputos temporales, tema al que se ligaban otros referentes a cuestiones cosmográficas y astronómicas (Lindberg, 2002: 346 y ss., Ordóñez, 2003: 218-223).

Este conjunto homogéneo de Repertorios recoge los conocimientos plasmados en las enciclopedias medievales examinadas, fuentes que se citan repetidamente en la exposición descriptiva de los contenidos que tratan. Por tanto, la conceptualización del tiempo y su división constatable en los autores renacentistas continúa el sistema establecido y transmitido por estas fuentes medievales. Este hecho conlleva necesariamente una distribución idéntica de los contenidos en todas las obras analizadas, e incluso la copia literal de pasajes completos en el caso de uno de los Repertorios, como podrá comprobarse.

\subsubsection{Chronographía o Reportorio de los tiempos (1545)}

Jerónimo de Chaves (Sevilla, 1523-1574), cosmógrafo de la Casa de la Contratación de cuya cátedra se hizo cargo entre $155^{2}$ y 1568, realizó una traducción del Tractatus de Sphera mundi de Juan de Sacrobosco, aunque su fama procede de su Chronographía o Reportorio de los tiempos (Sevilla, 1545)',

7 Manejamos la impresión sevillana de 1576 . 
que está dividida en cuatro partes: la primera trata del tiempo y sus divisiones, la segunda parte presenta el universo ptolemaico; la tercera incluye un cálculo del año eclesiástico además de otros datos astronómicos; la última parte se centra en la astrología y su influencia en la práctica de la medicina (apud López Piñero, 1983: s. v. Chaves, Jerónimo de).

En el primer tratado se aborda la división del tiempo en partes mayores (meses, años, lustros, eras, siglos y edades) y menores, que permiten subdividir las horas del día, cuyo estudio se desarrolla en cinco capítulos, del decimosexto al vigésimo, en los que se definen las voces objeto de análisis (átomos, uncias, momentos, puntos y cuadrantes), definiciones que van acompañadas de una explicación etimológica y la cita de la fuente compendiada. Las autoridades mencionadas son los clásicos Plinio y Aristóteles, e Isidoro y Beda ${ }^{8}$.

Los computistas antiguos dividieron el día natural en quatro partes, a quien llamaron quadrantes, y cada uno d'éstos contiene seys horas; $y$, assí, multiplicando quatro vezes seys, hazen veynte y quatro, que son las horas del día natural. Llamáronse estas partes quadrantes por similitud, porque assí como quadrans o quadras es la quarta parte de una libra $o$ asse, que contiene doze onças, las tres onças es el quadrante. A similitud d'esto, la quarta parte del día natural que contiene seys horas es llamada quadrante. (Chaves, 1576: 21r)

De la manera qu'el día natural fue diviso por horas y quadrantes, assí también la hora fue divisa de los antiguos en puntos. Y esta división dize Beda no ser natural, sino que se establesció assí de los antiguos por razón que, como los calculadores tuviessen necessidad de la división del día en partes, unas mayores, otras menores, inventaron vocablos con que nombrarlas, mediante los quales entendiessen las tales partes. Y assí, les plugo dividir la hora en quatro partes, a quien llamaron puntos, y son los que la gente vulgar llaman quartos de hora. (Chaves, 1576: 21v)

8 El benedictino Beda el Venerable (672-735) influyó en la formación de los autores de la Edad Media merced al carácter enciclopédico de sus producciones, entre las que destacan De temporibus liber y De temporum ratione (Enciclopedia universal ilustrada 1928: Beda). Para Ordoñez (2003: 209) ambos escritores «dedicaron esfuerzos a la aritmética, la geometría, la astronomía y la geografía y se preocuparon por resolver problemas del calendario y la medición del tiempo, pese a que la exposición de los problemas matemáticos y astronómicos, presentada de forma descriptiva y poco técnica, no ayudaba al lector, dada que la intención última de los autores era la correcta interpretación de las Sagradas Escrituras». 
Los antiguos dividieron cada uno de los puntos en diez partes, y cada una d'estas partes llamaron momento, a similitud del movimiento de las estrellas, como escribe sant Isidoro, el qual es muy tardío, y porque este espacio de tiempo es muy pequeño, por esto se llamó momento. (Chaves, 1576: 22r)

Qualquiera de los momentos ya dichos dividieron los antiguos en doze partes, a las quales llamaron uncias, por manera que la hora conteniendo quarenta momentos, contiene assimismo quatrocientas y ochenta uncias. Fueron llamadas uncias, a similitud de las que se usan en los pesos y medidas, y cada d'ellas vale tanto como la dozena parte de un asse o libra. (Chaves, 1576: 22r)

Las últimas y menores partes en quien los antiguos dividieron el día fueron en áthomos, en esta forma: cada una de las uncias dividieron en quarenta y quatro partes, a quien llamaron áthomos, vocablo griego que quiere dezir indivissible o impartible, no porque a la verdad no se puede yr haziendo división en infinito, como sea cuerpo continuo el que se mueve, y el tiempo también sea continuo, y de razón del continuo sea ser divissible en partes siempre divissibles, como dize Aristótiles, pero dízese que el áthomo es parte indivissible porque el entendimiento, puesto caso que entienda aquel processo en infinito, empero paresce cansar en la numeración de las tales partes y paresce con dificultad poderlas numerar. (Chaves, 1576: 22v)

Las explicaciones, como apreciamos, van acompañadas del recurso comparativo a otras medidas con una clara finalidad pedagógica, además de ser un mecanismo de creación neológica. Este empeño divulgador se manifiesta también por medio de reformulaciones con verbos denominativos como llamar o decir: «Les plugo dividir la hora en quatro partes, a quien llamaron puntos, y son los que la gente vulgar llaman quartos de hora» (Chaves, 1576: 21v).

\subsubsection{Repertorio de los tiempos (1554)}

En el año 1554 se imprime en Valladolid el Repertorio de los tiempos, el qual tura desde el año MDLIV hasta el año de MDXCII al cuidado de un religioso de orden de San Bernardo. El índice de este Repertorio resume la 
temática abordada: se inicia con los aspectos concernientes a la descripción de las divisiones menores del tiempo (cuadrantes, momentos, puntos, uncias y átomos) y de las otras mayores (años, meses, semanas y horas), para seguir con otros contenidos astrológicos relativos a los planetas, los signos zodiacales y el cómputo eclesiástico con el calendario de todas las fiestas de la Iglesia, donde se intercala la descripción de los meses propicios para las purgas y sangrías 9 , además de incluir una tabla de las más insignes ciudades de España y otros aspectos como las operaciones para medir con el báculo mensorio.

En este Repertorio anónimo se compendian en 72 folios de manera muy descriptiva los contenidos que están presentes en otras obras de este género.

Como sea estrangero d'estos reynos, aunque natural vassallo de nuestro César, he querido escrevir para los naturales d'esta provincia de España, adonde al presente bivo observando la regla del bienaventurado doctor Sant Bernardo. Solamente, amigo lector, me ha movido el zelo de la charidad, mayormente con aquéllos que en esta arte se han poco ocupado, y darles noticia y relación verdadera, en tan pequeño tractado, de las cosas más necessarias y útiles a la vida humana (Anónimo, 1554: IIr).

Como el mismo religioso reconoce en el Proemio se recopilan «algunas cosas a esta obra nescessarias, sacadas de muchos auctores, in salva providencia divina ac ecclesie correctione»; de hecho, los epígrafes concernientes a las unidades divisoras del día, así como los dedicados a la concepción del día natural, la división de los meses, años, etc. son exactamente idénticos a los incluidos en la Chronograpbia de Jerónimo de Chaves. Ello puede ser la prueba fehaciente de la reputación que adquirió el texto del sevillano, difusión advertida ya por López Piñero (1983), de modo que, con casi toda probabilidad, esta obra anónima no sea sino un resumen más accesible del tratado de Chaves en consonancia con los propósitos enunciados por el clérigo en el discurso antepuesto al cuerpo del libro ${ }^{10}$.

9 Nótese que la astrología en el mundo medieval y renacentista estaba estrechamente asociada con la práctica de la medicina (Lindberg, 2002: 353).

10 Esta aseveración tiene carácter preventivo hasta no efectuar un cotejo exhaustivo de ambos manuales. 


\subsubsection{Los tratados matemáticos de Juan Pérez de Moya}

De la obra más sobresaliente de Pérez de Moya, Aritbmética práctica y speculativa ${ }^{11}$, nos interesa especialmente el libro octavo, donde el matemático jienense realiza un compendio de las monedas, medidas y pesos usados desde la antigüedad y que está acompañado de datos históricos que evidencian la formación universitaria del autor. Después de destinar más de diez capítulos a describir los valores de algunas monedas españolas y las equivalencias de las medidas longitudinales, de capacidad y los pesos $^{12}$, en el capítulo 30 se consignan las «reglas para sacar las fiestas movibles»: «Porque no es otro mi intento sino dar reglas para saber el tiempo en que las fiestas (que dizen movibles) se han de celebrar, declaro primero qué cosa sea tiempo y cómo se divide» (Pérez de Moya, 1562: 647). En definitiva se agrupan materiales léxicos terminológicamente afines, según testimonia el trío peso, número y medida.

En el artículo séptimo incluye un breve listado terminológico con las definiciones de las «distancias de tiempo menores»:

Quadrans es la quarta parte del día natural, que es espacio de seys horas.

Puncto, en este propósito, es una quarta parte de una hora.

Momento es la décima parte del puncto o quarentena parte de una hora.

Uncia o minuto es una décima parte del momento.

Átomo es 1/48 abo de la uncia o minuto, y es lo que no recibe división, assí como el puncto en la línea. (Pérez de Moya, 1562: 659)

El matemático Pérez de Moya no ciñó su labor divulgadora exclusivamente a las matemáticas, pues en el Tratado de Mathemáticas en que se contienen cosas de Aritbmética, Geometría, Cosmograpbia y Philosopbia natural (1573) desarrolló cuestiones imbricadas tocantes a estas disciplinas, con citas de los más sobresalientes tratadistas en cada ámbito científico y con datos históricos que ponen de manifiesto su erudición. En el capítulo XXXVIII del primer tratado De Aritmética expone la temática que nos ocupa y en sus artículos Pérez de Moya (1573) dispone las definiciones de este vocabulario:

11 La Aritmética llegó a alcanzar 30 ediciones (hasta 1875) y contiene cálculo mercantil, aritmética, álgebra y geometría práctica, a la vez que acumula un nutrido material de notable interés (apud López Piñero, 1983: s. v. Pérez de Moya, Juan).

En Sánchez Martín (en prensa) nos ocupamos del análisis de esta terminología. 
Áthomo es vocablo griego, quiere dezir cosa no divisible o impartible, no porque con el entendimiento no se pueda dividir y partir en infinito pues procede de cuerpo continuo, y la quantidad continua en diminución no es finita, como en el tratado de Geometría se dirá. Más dize no ser divisible el áthomo, porque según la diminución d'esta parte parece ser difficultoso de poderse numerar, y es tan pequeña que quarenta $\mathrm{y}$ ocho áthomos constituyen y hazen una uncia.

Uncia dizen a una duodécima parte del momento, de modo que doze uncias hazen un momento.

Momento dixeron los antiguos a la décima parte del punto, de suerte que diez momentos hazen tanto como un punto.

Punto es una quarta parte de una hora, de suerte que quatro puntos hazen una hora. Es lo que dezimos quarto de hora.

Hora es la sexta parte del quadrante, o vigésima quarta parte de un día natural.

Quadrante, dizen a la quarta parte del día natural, es tiempo o espacio de seys horas. (Pérez de Moya, 1573: 720-722)

\subsubsection{Chronographía y Repertorio de los tiempos a lo moderno (1585)}

Finalmente, el cosmógrafo tudelano Francisco Vicente de Tornamira compuso su Chronographía y Repertorio de los tiempos a lo moderno, el qual trata varias y diversas cosas, de Cosmografía, Sphera, Theórica de Planetas, Pbilosopbia, Cómputo y Astonomía, donde se conforma la Astrología con la Medicina y se ballarán los motivos y causas que ha avido para reformar el año destinada a revisar todos los elementos cosmográficos y astronómicos que intervienen en el cómputo del tiempo ${ }^{13}$. Como otros científicos coetáneos inserta un capítulo en el que reproduce, pero sin citar fuentes, las divisiones de las horas:

Los computistas dividieron el día natural en 4 quadrantes, que cada uno contenía 6 horas y cada hora dividieron en 4 puntos, o quartos que dezimos de hora. [...] cada punto tornaron a

13 A él debemos una traducción del Kalendario gregoriano del latín al español con ciertas adictiones $y$ comentos al fin de cada uno de sus cánones (Pamplona, 1591) (Enciclopedia universal ilustrada, 1928: s. v. Tornamira). 
dividir en 10 momentos. Otros dan más puntos y momentos a la hora, pero esta es la división que generalmente guardan los computistas, los quales dividieron cada momento en 12 uncias o onças. Estas uncias dividen también cada una en 44 áthomos, que es la última y menor división que hazen del tiempo, que quiere decir en griego, indivisible (Tornamira, 1585: 375 )

\section{Análisis terminológico y recepción lexicográfica}

En la historia de toda disciplina científica los conceptos han sido y son muy importantes, pero no cabe duda de que la terminología empleada para verbalizarlos también lo es. Lo primero que debe constatarse es que las unidades léxicas examinadas son poliparadigmáticas (Salvador, 1988:645), hecho percibido en el corpus estudiado donde leemos: «Y muchas vezes los escriptores en la división del tiempo usan de los vocablos que competen a los pesos y medidas» (Chaves, 1576). Por tanto, los términos latinos uncia o cuadrante denotan medidas de longitud, capacidad o peso, pero funcionan a la vez dentro del ámbito nocional 'tiempo'. En otros casos, como en punto, observamos el frecuente desplazamiento semántico que va desde el significado espacial a la expresión de la temporalidad, cambio semántico advertido por Santos Domínguez y Espinosa Elorza (1996). Luego es patente la vinculación semántica establecida en esta terminología.Si partimos de la división del día en 24 horas, 12 diurnas y otras 12 nocturnas, entendemos que se recurra al módulo ponderal por excelencia en la metrología clásica. Ya Nebrija en sus nomenclaturas metrológicas anota la variabilidad semántica del as romano, módulo empleado en la medición de diversas magnitudes (peso, espacio y tiempo): «As pro libra siue nummo non est certi cuisdam ualoris: sed pro temporum diuersilatc uariat. Cum uero solidum quidpiam puta magnitudines, numeros, tempora, spacia hereditatesque designat» (Nebrija, 1511); y enumera sus múltiplos entre los que se encuentran el quadrante (Quadrans, quarta pars) y la uncia (Vncia, pars duodecima).

Ambas voces cuentan con entrada en la Repetitio sexta donde observamos su multiplicidad semántica. Por un lado, el cuadrante constituye un módulo utilizado en la designación de medidas de longitud, superficie, peso, capacidad, incluida la temporal 'cuarta parte del día': «Quadrans quarta pars est assis siue cuiuscunque alterius solidi, puta pedis, iugeri, horae, diei, anni ut si dixeris quos annus constat ex tercetum septaginta (sic) quinque diebus \& quadrante, id est, sex horis» (Nebrija, 1510) ${ }^{14}$.

14 «Quadrans. Quart de l'as (= trois onces); et l'as étant consideré comme unité; quadrans 
De igual modo, uncia es un término polisémico que, además de aplicarse a los módulos de peso y de capacidad ${ }^{15}$, posee el significado temporal 'duodécima parte del momento'. Como tuvimos ocasión de comprobar, en los tratados científicos examinados se describen estas correspondencias designativas.

El término punto cubría en latín igualmente campos semánticos muy variados, según leemos en A Latin Dictionary (Lewis, 2002): «punctum. 2. A small part of anything divided or measured off, e. g. a. A small weight. b. A small liquid measure. c. A small portion of time, an instant, a moment (cf. momentum)». El límite mínimo de cualquier extensión en geometría está representado por el concepto de punto 'límite mínimo de la extensión', de donde procede la conceptualización del punto temporal definido como 'momento, instante', esto es, 'límite mínimo de la duración', relación que confirmamos en Autoridades (Real Academia Española, 1726-39: s. v. punto): «Y en la duración del tiempo todos los instantes o momentos son puntos». Queda reflejada una vez más la evolución de las nociones espaciales a las temporales, así como las relaciones semánticas establecidas entre los módulos metrológicos.

Por su parte, el diccionario etimológico de Ernout y Meillet (1979: s. v. moveo) acoge también la acepción especializada de momentum que se define como 'petit division du temps' y su relación sinonímica con la voz punto: «momentum (temporis), synonyme de punctum».

En este caso se ha procedido desde el sentido concreto que posee el término en latín 'movimiento' (momentum < moveo + mentum) al significado abstracto 'tiempo de duración indeterminada'. Ya comprobamos cómo los científicos renacentistas recurrían para explicar su significado a la propuesta etimológica formulada por San Isidoro: «Los antiguos dividieron cada uno de los puntos en diez partes, y cada una d'estas partes llamaron momento, a similitud del movimiento de las estrellas, como escribe sant Isidoro, el qual es muy tardío, y porque este espacio de tiempo es muy pequeño, por esto se llamó momento» (Chaves, 1576: 22r).

Hay una última medida de las horas del día que no admite división alguna y para cuya verbalización se recurrió al término acuñado por Demócrito,

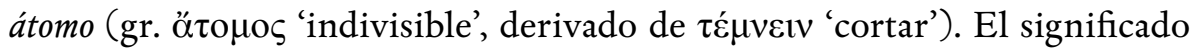

s'est employé pour désigner le 'quart' de un tout: iugerum, libra, sextarius, pes, dies, etc.» (Ernout-Meillet, 1979: s. v. quattuor).

15 «Vncia duodecima pars est assis siue cuiuscunque solide, unde \& uasorum capacitas unciis distinguebatur \& pes ipse omnium mensurarum mensura in duodecim uncias diuisus est» (Nebrija, 1510). 
etimológico está en la definición plasmada en los diccionarios del español desde Nebrija (1492): «atomus.i. por el atomo no partible». Sin embargo, la necesidad de designar un nuevo concepto, condujo a los autores medievales a dotar a este significante de un nuevo significado 'unidad temporal correspondiente a la cuarentaioctava parte de la uncia', sentido no admitido en los diccionarios ${ }^{16}$. Esta equivalencia se toma a partir del valor del óbolo que era una unidad divisora de la uncia «Vncia duodecima pars libre romane siue assis in quacunque significatione accipiarur as. Constat autem siliquis centum quadraginta quattuor; scrupulis uiginti quattuor; drachmis octo sextulis sex; duellis tribus; siciliquis quattuor; obolis quadraginta octo» (Nebrija, 1511).

Con respecto a la recepción lexicográfica de los términos restantes, como vemos en la tabla adjunta, todos los diccionarios seleccionados muestran el empleo de bora, momento y punto como medidas del tiempo, aunque no todos ellos registran los valores de estas unidades. No obstante, gracias a las obras lexicográficas podemos estudiar las evoluciones semánticas que estas voces han experimentado.

Por ejemplo, en el caso de hora asistimos a las conexiones establecidas entre distancia y tiempo: «vigésima cuarta parte del día natural» y «espacio de camino que se anda en una hora» (Real Academia Española, 1726-39), cuya longitud Terreros estima en una legua.

Por lo que respecta a punto, confirmamos igualmente la evolución de lo espacial a lo temporal: el primer sentido registrado es el referido al punto geométrico, pero los repertorios dieciochescos contemplan el uso temporal del término: el académico sigue la acepción etimológica de la voz latina 'duración del tiempo, instante, momento' coincidiendo con Nebrija («Punto de tiempo. momentum.i.instans»), mientras que Terreros (1786-1793) marca la acepción como perteneciente al ámbito de la gnomónica: «Se dice de las divisiones de las horas de un relox».

Finalmente, los diccionarios de la Academia y de Terreros no incluyen la acepción temporal de los términos cuadrante y uncia, pero sí sus valores como unidades monetarias y ponderales.

Esta pequeña cala pone de relieve que los repertorios lexicográficos son testigos de los distintos procesos de cambio sufridos por esta terminología en

16 Garriga (2008: 111) sí advierte que el Diccionario enciclopédico de Gaspar y Roig (1853) define átomos como «ant. Partes pequeñísimas de las horas». 
el plano del contenido y, en definitiva, que por estas razones los diccionarios son materiales imprescindible para su estudio.

\section{Conclusión}

En síntesis, el estudio de la documentación textual y lexicográfica manejada pone de manifiesto dos aspectos esenciales. Primero, que la conceptualización metrológica clásica, también en lo concerniente a la temporalidad, se transmite durante la época medieval y pervive en el Siglo de Oro. En segundo lugar, evidencia los vínculos existentes entre los distintos módulos metrológicos y las unidades temporales, así como las evoluciones semánticas espacio-temporales sufridas por estos significantes léxicos. 


\begin{tabular}{|c|c|c|c|}
\hline 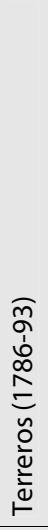 & 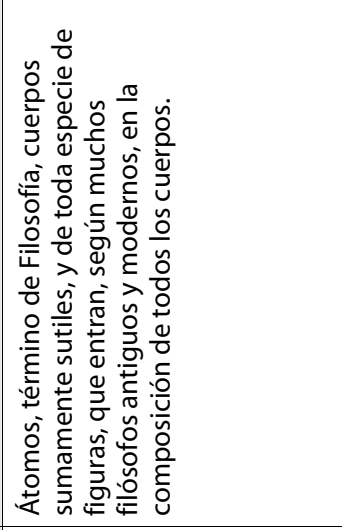 & 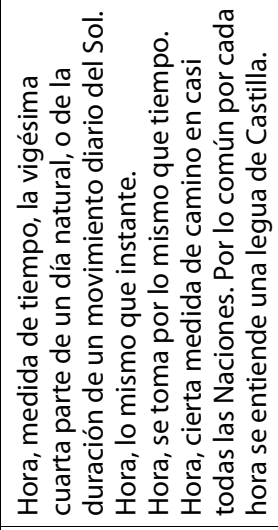 & 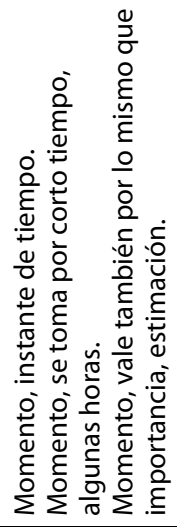 \\
\hline 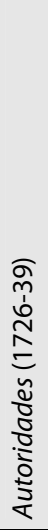 & 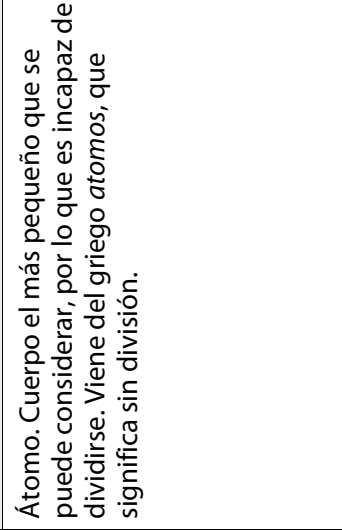 & 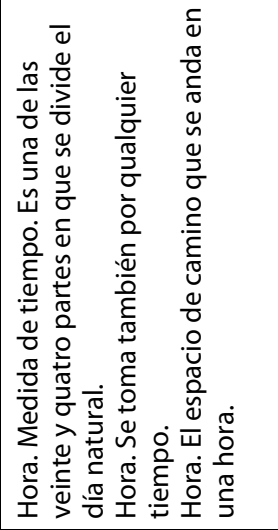 & 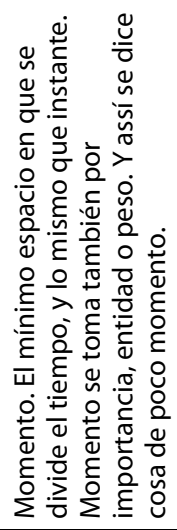 \\
\hline $\begin{array}{l}2 \\
\overline{0} \\
气 \\
\frac{n}{0} \\
\frac{\pi}{0} \\
\frac{2}{2} \\
0 \\
0 \\
0\end{array}$ & 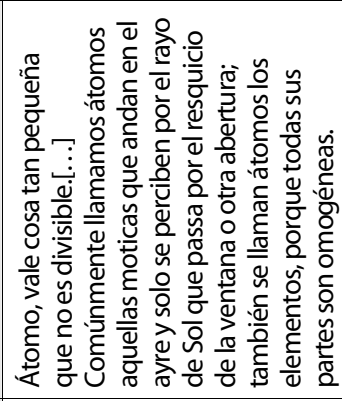 & 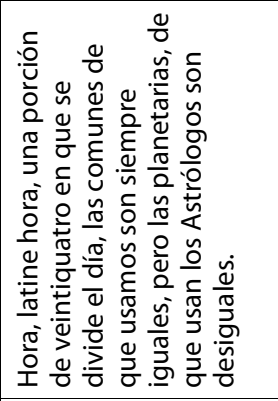 & 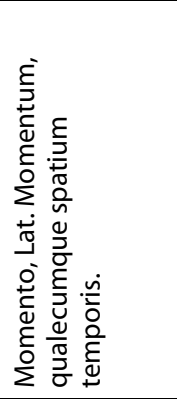 \\
\hline 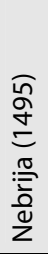 & 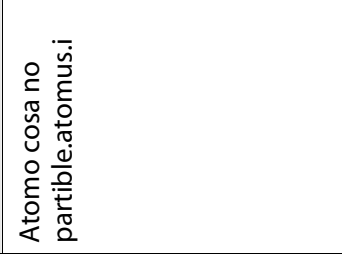 & 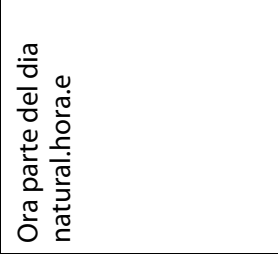 & 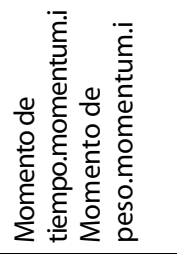 \\
\hline
\end{tabular}




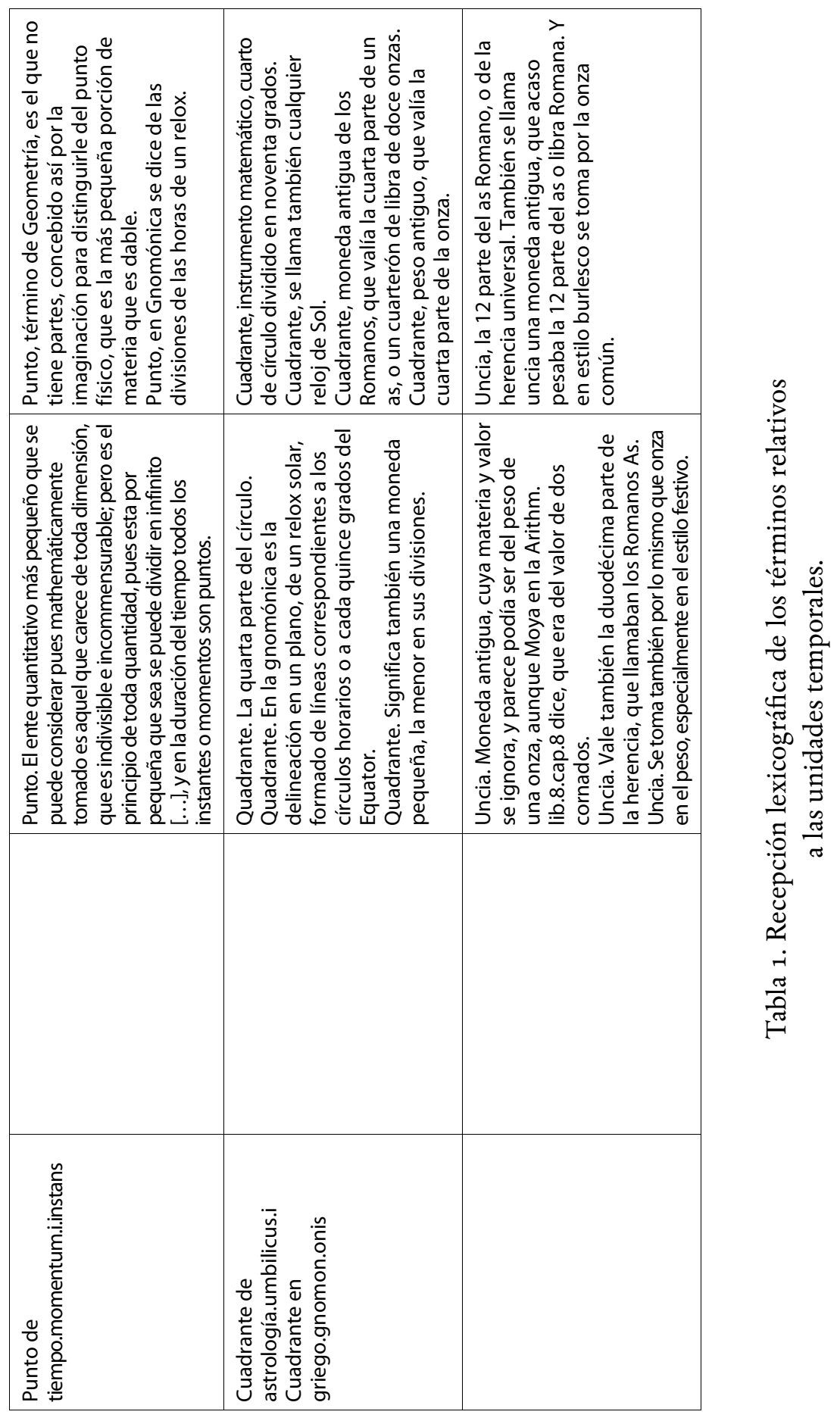




\section{Bibliografía}

Anónimo (1554): Repertorio de los tiempos. Valladolid: Francisco Fernández de Córdova.

Collado de Lebrixa, L. (1592): Plática manual de Artillería. Milán: Pablo Gotardo Poncio.

Corominas, J., Pascual, J. A. (1980-1991): Diccionario crítico etimológico castellano e bispánico (DCECH). Madrid: Gredos.

Covarrubias, S. de ([1611] 1995): Tesoro de la Lengua Castellana o Española. Madrid: Castalia.

Enciclopedia universal ilustrada europeo-americana (1928). Madrid: Espasa Calpe.

Ernout, A., Meillet, A. (1979): Dictionnaire étymologique de la langue latine: bistoire des mots. París: Klincksieck.

Garriga, C. (2008): «Notas sobre la historia de la voz átomo». En: Revista de Investigación Lingüística, 11, 95-124.

Gutiérrez Rodilla, B. (2007): La esforzada reelaboración del saber. Repertorios médicos de interés lexicográfico anteriores a la imprenta. San Millán de la Cogolla: Cilengua.

Lewis, Ch. T. (2002): A Latin Dictionary. Oxford: Clarendon Press.

Lindberg, D. C. (2002): Los inicios de la ciencia occidental. La tradición cientifica europea en el contexto filosófico, religioso e institucional. Barcelona: Paidós.

López Piñero, J. M. a et al. (1983): Diccionario bistórico de la ciencia moderna en España. Barcelona: Península.

Martínez de Burgos, A. (1551): Reportorio de todas las premáticas y capitulos de Cortes (1523-1551). Medina del Campo: Guillermo de Millis.

Medina, P. (1545): Arte de navegar. Valladolid: Francisco Fernández de Córdova.

Muñoz Box, F. (2002): «El tiempo y la medida del tiempo». En: Luis García Ballester (dir.), Historia de la Ciencia y de la Técnica en la Corona de Castilla. Edad Media. Salamanca: Junta de Castilla y León, 539-550.

Nebrija, A. de ([1492] 1979): Diccionario latino español. Barcelona: Puvill.

Nebrija, A. de ([1495] 1951): Vocabulario español-latino. Madrid: Real Academia Española.

Nebrija, A. de ([1510] 1981): Repetitio sexta de mensuris. Introducción y traducción de J. Costas Rodríguez. Salamanca: Universidad de Salamanca. 
Nebrija, A. de (1511): Repetitio septima de ponderibus. Introducción de P. Díez de Revenga y M. Á. Puche Lorenzo: http://interclassica.um.es (16-092011).

Ordóñez, J. (2003): «Antigüedad y Edad Media». En: Javier Ordóñez, Víctor Navarro, José Manuel Sánchez Ron, Historia de la ciencia. Madrid: Austral, 13-229.

Oroz Reta, J., Marcos Casquero, M. (1982-1983): Etimologías. San Isidoro de Sevilla. Introducción general de Manuel Díaz. Madrid: Biblioteca de Autores Cristianos.

Pérez de Moya, J. (1562): Aritbmética práctica y speculativa. Salamanca: Mathías Gast.

Real Academia Española ([1726-1739] 1990): Diccionario de Autoridades. Madrid: Gredos.

Salvador, G. (1988): «Lexemática histórica». En: Manuel Ariza, Antonio Salvador, Antonio Viudas (eds.), Actas del I Congreso Internacional de Historia de la Lengua Española. Madrid: Arco/Libros, 635-646.

Sánchez González de Herrero, M. ${ }^{a}$ N. (ed.) (2007): De las partes de la tierra y de diversas provincias o las versiones castellanas del libro XV de 'De proprietatibus rerum' de Bartolomé Ánglico. Vigo: Academia del Hispanismo.

Sánchez González de Herrero, M. ${ }^{a}$ N., Herrera, M. ${ }^{a}$ T. (eds.) (1999): Textos y Concordancias del Libro de las propiedades de las cosas de Bartolomé de Glanville. Madison: Hispanic Seminary of Medieval Studies.

Sánchez Martín, F. J. (en prensa): «La metrología renacentista: análisis científico y lexicográfico». En: Verba.

Santos Domínguez, L., Espinosa Elorza, R. (1996): Manual de semántica bistórica. Madrid: Síntesis.

Terreros y Pando, E. ([1786-1793] 1987): Diccionario Castellano con las voces de las Ciencias y las Artes. Madrid: Arco/Libros.

Tornamira, F. V. (1585): Chronographía y Repertorio de los tiempos a lo moderno. Pamplona: Thomas Parralis de Savoya. 
Francisco Javier Sánchez Martín

University of Murcia

\section{The smallest divisions of time: terminological and lexicographical aspects}

Keywords: Terminology, Lexicology, Lexicography

This study of the ancient divisible units of the hours of day (the terms borrowed from latin: átomo, cuadrante, momento, punto and uncia) use the principal sources of the medieval and Renaissance works. With regard to the former, an example of the cultural transmission of this specialized lexicon can be seen in its reception in The Etymologies of Saint Isidore (c. 560-636) and in the Libro de las propiedades de las cosas of Bartolomé Ánglico (1240), an encyclopaedia that had an extraordinary reception in Western Europe until the sixteenth century. Amongst the Renaissance sources several studies stand out: Chronographia or Reportorio de los tiempos (1545) by Jerónimo de Chaves, the anonymous book Repertorio de los tiempos (1554) and Chronograpbia y Repertorio de los tiempos (1585) by Francisco Vicente de Tornamira), a set of treatises which includes the knowledge compiled in the medieval encyclopaedias mentioned above. These works allow us to verify the transmission of this lexicon, in a stage marked by the growing interest in metrological issues. The analysis of this terminology reflects the semantic connections established between the various dimensions (weight, space and time) as its semantic reference moves from the spatial domain to the that of time and relationships are attested in the earliest dictionaries of the Spanish language. 
Francisco Javier Sánchez Martín

Univerza v Murciji

\section{Manjše merske časovne enote: terminološki in leksikografski vidiki}

Ključne besede: terminologija, leksikologija, leksikografija

Avtor članka obravnava starodavne merske enote za ure dneva, pri čemer se opira na osrednje srednjeveške in renesančne vire. Pri srednjeveških se osredotoči na recepcijo tega specializiranega besedišča v enciklopedičnih delih Svetega Izidorja Seviljskega (c. 560-636), Etymologiae, ter Bartholomaeusa Anglicusa (1240), De proprietatibus rerum, delu, ki je imelo do 16. stoletja v Zahodni Evropi izredno pomembno vlogo. Pri renesančnih virih avtor izpostavi več študij, ki vključujejo zbrana znanja iz omenjenih srednjeveških enciklopedij: Chronograpbía ali Reportorio de los tiempos (1545) Jerónima de Chavesa, Repertorio de los tiempos (1554) anonimnega avtorja in Chronograpbia y Repertorio de los tiempos (1585) Francisca de Vicente Tornamira. Ta dela omogočajo uvid v način širjenja obravnavanega besedišča v obdobju čedalje večjega zanimanja za meroslovna vprašanja. Študija terminologije pokaže semantične povezave, vzpostavljene med različnimi dimenzijami (teža, prostor in čas), kot tudi semantični razvoj, ki gre iz prostorskega obvladovanja $\mathrm{k}$ izražanju časovnosti. Slednje je razvidno že v prvih slovarjih španskega jezika. 